Lüders, M. (2020). Innovation \& creativity: Media as business and commons. In M. B. von

Rimscha (Ed.), Management and Economics of Communication (pp. 223-240): De Gruyter.

Marika Lüders

\title{
12 Innovation \& creativity: Media as business and commons
}

\begin{abstract}
This chapter argues that research on media innovations benefits from combining insights and concepts from the business literature with the critical theory approach typical of media and communication studies. Business, economics and marketing literature rarely address innovations in media industries, and communication and media scholars seldom look beyond their own disciplinary boundaries when studying media innovations. This chapter first reviews how the interrelated notions of innovation and creativity are conceptualized in the literature, and next how innovation and creativity apply to media industries. Using music streaming services as a case, I argue how innovation and business literature provides perspectives useful for understanding the development and adoption of these services. Key notions include a turn to experience-centric approach to innovation, customers as co-producers of service-value, and the context of innovation extending to include multiple actors and their interactions. Whereas the innovation literature has much to offer, media and communication scholars are likely better positioned to investigate media innovations than scholars from the business and marketing fields. This is due to the pro-innovation bias and lack of critical approaches in the innovation literature. A core concern for the study of media innovations is therefore to also question innovation.
\end{abstract}

Keywords: Business management, Business models, Business model innovation, Creativity, Critical innovation studies, Customer-centric, Experience-centric

Fast Company's 2018 edition of the world's most innovative companies ranks the media streaming services Netflix and Spotify as the second- and ninth-most innovative (Fast Company 2018). The business models of these companies share similarities with regard to their core value propositions, their global reach, and having contributed to changing how audiences access media content. Clearly, choosing Fast Company's list of most innovative companies is a bit of cherry-picking; numerous rankings are made each year with different companies featuring as "most innovative". The point here is not to take these rankings at face value, but merely to state what may seem obvious: In a matter of just a few years these two companies have become the epitomes of a remarkable shift in how content finds audiences, and moreover an apparent (though not necessarily accurate) victory on the "war on piracy". As such, we might initially use these two companies as examples of the importance of innovation and creative change thinking for solving pressing challenges and making the most of technological opportunities. 
In the context of innovation, creativity concerns the generation of novel and useful ideas (Amabile 1988). Innovation in turn is defined as the successful implementation of new ideas, products, processes, or services (Amabile 1988; Hurley and Hult 1998; Thompson 1965). It is depicted as a core requirement for any company hoping to remain in the market (Drucker 1985), and the main factor behind economic growth. Innovation is hence intrinsically linked to the belief in free markets and continued economic growth as the means to achieve human progress. However, whereas most commercial media organizations face profit requirements, the dual role of media industries in providing content and services for the common good of society and delivering profit to shareholders implies that studies of media innovations ought to include critical approaches: Is innovation always for the better? And for whom is innovation better (citizens, societies, democracy, companies, profit-maximization)?

In this chapter, I argue that media innovation research benefits from combining insights from the business literature on innovation and creativity with the critical theory approach typical of media studies. This chapter is hence an exercise in broadening the scope of media innovation research towards the fields of business management and marketing, yet with the explicit objective of delineating how media as commerce and commons require subtleness in such endeavors. First, I will turn to how the interrelated notions of innovation and creativity are defined and conceptualized in existing literature, expanding beyond the field of media and communication studies. I will thereafter turn to how innovation and creativity apply to the media industry. The chapter ends with a discussion about an emerging trajectory of critical innovation studies seeking to counter-balance the pro-innovation bias typical of studies on innovation.

\section{Innovation and the innovation process}

Whereas innovation appears inherently human (Fagerberg 2006), the organized form of innovation typical since the advent of industrialization rapidly accelerated the speed of innovation (Kline and Rosenberg 1986). The scholarly interest in innovation has seen a steady growth, represented for example by a steep increase in the number of articles on innovation in business and economics journals (Crossan and Apaydin 2010). This increase in scholarly interest is accompanied by various conceptualizations and operationalizations of the notion of innovation, and numerous typologies of types of innovations (for reviews, see Crossan and Apaydin 2010; Garcia and Calantone 2002). Starting with the simple definition of innovation as the implementation of a new idea, product, or process, it is apparent that this definition eludes the complex and far-from-straightforward process of what comes before implementation. As such, the many definitions of innovation processes might be a symptom of how these processes differ depending on the type of innovation: A product innovation process might 
depend on different forms of competences, capabilities, skills, forms of creativity, and technological advance compared to a process innovation or service innovation. Part of the challenge in conceptualizing innovation is hence the need to distinguish between different types of innovations. Attempts to distinguish between types of innovation roughly reflect two questions: What is being innovated, and how radical is this change compared to the state of the art?

With regard to the first question, innovations certainly apply well beyond innovations in goods or products. Francis and Bessant (2005) distinguish between innovations in products/services, processes, position, or paradigm. In their typology, product innovation refers to changes in the products or services that an organization offers; process innovation refers to changes in the ways in which products/services are created and delivered; position innovation refers to changes in the context in which the products/services are introduced; and paradigm innovation refers to replacing traditional belief systems with a new way of understanding and reframing business. Innovations in paradigms include innovations in business models - a field of research that has seen a remarkable upsurge of interest in recent years (see Foss and Saebi 2017 for a review). Business models specify a firm's value proposition, the target segments addressed, the structure of the value chain or networks required for realizing the value proposition, and the firm's value-capture mechanisms (Saebi et al. 2017). Business model innovation hence refers to innovation in any of these components, and how changes in one component reflect or necessitate changes in others.

With regard to the second question (how radical this change is compared to the state of the art), management scholars often use the notion of radicalness to denote the degree of newness of an innovation compared to existing offerings in the market. The radicalness of an innovation is closely related to changes in technology (Dewar and Dutton 1986). Hence radical innovations represent revolutionary and risky changes in technology, which in the next step implies the introduction of innovations that depart from existing practices (Dewar and Dutton 1986; Ettlie, Bridges, and O'Keefe 1984). Thus, it follows that incremental innovations refer to the continuous improvements of types of innovations that may be caused by technological improvements and adjustments (Green and Cluley 2014; McDermott and O’Connor 2002).

The distinction between incremental and radical innovations has been productive and has also enabled scholars to unpack the effects of organizational structure and practice on innovation (Green and Cluley 2014). However, we might question whether the notion of radical innovation is based on a too naïve understanding of technological development (Lüders et al. 2017). That is, whereas the management literature on innovation links innovation closely to technological development and advancement, this link appears to be characterized by too deterministic accounts of the role of technology for innovation. An exception is Christensen's (1997) distinction between innovations based on disruptive technologies and innovations based on sustaining technologies, which represents a useful alternative and one which might be particularly relevant for innovations in media industries. Christensen argues that disruptive 
innovations are first underperformers compared to established mainstream products, "but they have other features that a few fringe (and generally new) customers value. Products based on disruptive technologies are typically cheaper, simpler, smaller, and, frequently, more convenient to use" (Christensen 1997: XV). The appeal of his theory is the process view on technological development, acknowledging that "new technology" does not emerge full-fledged and perfect. Once the technology matures and the innovation meets the quality standards of the mainstream customers, disruptive innovations intersect with the needs of the majority of the customers and may ultimately displace the mainstream products of incumbents in the market. Netflix serves as a good example: The service was launched in 1997 as an online service for renting movies with DVD delivery through postal mail. This way of renting movies was slow and cumbersome and did not appeal to mainstream customers. It was only with the process of turning Netflix into a streaming service with a fixed monthly fee for an "allyou-can-watch" offer that the company became attractive to mainstream customers (Christensen, Rayonr, and McDonald 2015).

Regardless of the type of innovation, innovation processes are not smooth and linear, but rather characterized by uncertainty and disorder, and an innovation rarely has a clear entry-point in time in terms of entering the market (Kline and Rosenberg 1986). Likewise, studies on innovation within the fields of management, economics, marketing, and organizational studies tend to point to the complexity and riskiness of innovation, and to the apparent constant need to innovate in order to be able to stay in the marketplace (Christensen 1997; Drucker 1985; Lüders et al. 2017; Tidd, Bessant, and Pavitt 2005). Innovation is hence not easy, but it is imperative (Tidd, Bessant, and Pavitt 2005), and innovation is considered and found to be one of the key factors for a successful firm. Relatedly, the capacity to innovate has a decisive impact on business performance (Hult, Hurley, and Knight 2004; Schumpeter [1912] 2017; Hurley and Hult 1998).

Attempts to innovate are attempts to forecast what the future entails and what customers may want. Innovative capabilities thus include creative change thinking as well as being attentive and outward-looking. However, skills to pick up signals of change and to exploit external sources of knowledge are only part of the story. In their seminal article, Cohen and Levinthal (1990) introduced the notion of a firm's absorptive capacity as its ability to exploit and act upon external knowledge as a key component of innovative capabilities. This firm-level absorptive capacity depends on the capacities of its individual members, but also "on transfers of knowledge across and within sub-units that may be quite removed from the original point of entry" (Cohen and Levinthal 1990: 131-132). In any organization, one of the challenges consequently is to bridge and connect the different units, or to bridge the structural holes that emerge between different groups of people, where each group embodies information and knowledge that may be non-redundant to the other groups. Relatedly, the ability to come up with or act upon creative and innovative ideas relies on import-export actions across structural holes (Burt 2004). 
An emphasis on business performance, defined as "the achievement of organizational goals related to profitability and growth in sales and market share, as well as the accomplishment of general firm strategic objectives" (Hult, Hurley, and Knight 2004: 430-431), indicates the importance of business-centric metrics as the primary motivation for why companies need to innovate. However, innovations such as new products, services, and processes regularly also make a difference for customers, who need to be convinced that "new" means "better, convenient, worth the price", and sometimes that the inconvenience of changing from one service to another is worth it. An additional complicating factor in terms of uncertainties of innovation is that customers do not necessarily adopt innovations even if these provide a better product or service (Heidenreich, Kraemer, and Handrich 2016). In the marketing literature, the notion of customer switching or churn has been extensively studied, where both monetary equity and customer psychology (cognitive, social, and affective aspects) are considered important for explaining why and when customers do or do not switch (see Kristensson, Nysveen, and Thorbjørnsen 2017 for a review).

Aligned with this awareness of the unpredictability of customers as the makeit-or-break-it stakeholders is the alleged increasing recognition of putting customers first. A core trajectory and thesis within the management and marketing literature over the last decades is the move from a company- and efficiency-centric to a customer- and experience-centric company (see, e.g., Pine and Gilmore 1999; Prahalad and Ramaswamy 2004). Given the unique and contextual character of customer experience, service providers depend on a continuous dialogue with customers (or with the audience/recipients, if applied to the field of media) to understand their needs and to update their offerings accordingly. By implication, this means that while profit-optimization and efficiency-optimization remain core incentives to innovate, the outcomes of innovation tie in closely with pleasing customers, i. e., with moving beyond business performance as more or less a measure of pleasing shareholders to a realization that pleasing shareholders can only be achieved by pleasing customers. A similar approach, also from the field of marketing, is the service-dominant logic, providing an analytical lens to understand how marketing has moved from a goods-dominant to a service-dominant view (SD-logic), implying that service value is always co-created with customers. Value is hence proposed by a service provider, but always determined by a service beneficiary (e. g., a customer): The recipient actor, as an operant resource, is as such capable of acting on other resources to create value in use (Vargo, Maglio, and Akaka 2008; Vargo and Lusch 2004). The SD-logic forms the backbone for the subsequent service ecosystem approach, which conceptualizes innovations as the co-creation of "practices that provide novel solutions for new or existing problems" (Akaka, Vargo, and Wieland 2017: 54). From this perspective, innovation is hence not so much an output, but rather a collaborative process involving and integrating a number of actors as operant resources. This approach has evident similarities to Csikszentmihalyi's Systems Model of Creativity, which I will address in the next section. 


\section{The role of creativity in innovation}

If innovation is the successful implementation of new ideas, products, processes, or services, then the ideas, hunches, and inspirations for potential innovations must come from somewhere. Creativity can be considered one of the "sources" of innovation, yet innovation is more than a creative process, and definitions of innovation(s) (albeit numerous) all tend to point to the necessity of the application, exploitation, or commercialization of what is new, changed, or improved (Amabile 1988; Anderson, Potočnik, and Zhou 2014; Csikszentmihalyi and Sawyer [1995] 2014; Crossan and Apaydin 2010). In discussing the role of creativity in innovation, I will now turn to two formative scholars within the field, Amabile and Csikszentmihalyi, whose longterm studies have provided insights that both overlap and diverge in their emphasis on what creativity is and where it can be found. Amabile and in particular Csikszentmihalyi also play a formative role in how media and communication scholars have conceptualized creativity (see, e.g., Küng 2008; McIntyre 2012).

Amabile (1988: 126) defines creativity as "the production of novel and useful ideas by an individual or small group of individuals working together”. In Amabile's account, creativity thus resides in individuals and is a crucial but not sufficient element of organizational innovation. In Amabile's model of creativity and innovation in organizations, individual creativity is depicted as associated with three components: domain-relevant skills (e. g., knowledge, technical skills), creativity-relevant skills (e.g., persistence, risk orientation, cognitive-explorative skills), and intrinsic motivation. Each component is necessary but not sufficient for creativity in and of itself. In the next stage, Amabile's componential model of creativity is included as a required element in a general model of organizational innovation. Organizational level components include the motivation to innovate, resources in the task domain, and skills in innovation management. Both individual components and organizational components are situated within stages of the innovation process. Amabile's model is admirably clear on distinguishing creativity as part of the innovation process, and her empirically solid insights on the components of creativity with an emphasis on the need for a baseline domain knowledge and intrinsic motivation have been corroborated by later research (see Anderson, Potočnik, and Zhou 2014 for a review). Although Amabile's model of creativity goes beyond the individual, we might question how far we get by primarily understanding creativity on the level of individuals.

Csikszentmihalyi's (2014) Systems Model of Creativity retains the individual level as important, yet situates creativity in a much larger societal context. Csikszentmihalyi ([1988] 2014: 47) does not so much ask what creativity is, but where creativity is. The question of where creativity is cannot be answered merely by pointing to a person or a person's (or organization's) work; instead, creativity is the result of interactions between three systems: a set of social institutions that selects the works worth preserving; a stable cultural domain that preserves and transmits selected works to following generations; and the individual (or group of individuals) who brings about 
a change considered to be creative. "Without a culturally defined domain of action in which innovation is possible, the person cannot even get started. And without a group of peers to evaluate and confirm the adaptiveness of the innovation, it is impossible to differentiate what is creative from what is simply statistically improbable or bizarre" (Csikszentmihalyi [1988] 2014: 48). Csikszentmihalyi may in this instance seem to use innovation and creativity as interchangeable notions. Still, elsewhere he is quite clear on situating innovation as a trait of entire organizations as the innovation process requires investments in order to turn creative ideas into implemented innovations (Csikszentmihalyi and Sawyer [1995] 2014).

The core thesis of Csikszentmihalyi's systems model posits that creativity extends beyond the individual and can only be fully grasped by including the system surrounding the individual level. The "person" level is important, but it is also the level requiring the least attention, being the best known (Csikszentmihalyi [1988] 2014: 59). Still, even at this level, the contribution of the individual is tightly connected to the system level in producing "some variation in the information inherited from the culture” (Csikszentmihalyi [1988] 2014: 51). Humans cannot create ex nihilo. Instead, creativity in the minds of human agents is seen as causing and being caused by something else, i. e., creating is as much about re-creating as it is about creating something new and absolutely original. Moving from an individual definition of creativity to a system-level or sociocultural definition of creativity also implies moving beyond the organization. Only relevant social groups can collectively determine the novelty of an individual creation, and only relevant social groups can determine whether a novelty is appropriate or recognized as socially valuable in some way (Sawyer 2012).

\section{Innovation and creativity in the media sector}

Research addressing topics of innovation, creativity, and innovation processes in the business, economics, and marketing literature rarely concerns the media industry sector (Dogruel 2014). Relatedly, communication and media scholars rarely investigate the media industries with an explicit focus on innovation and innovation processes, or, more precisely, scholars addressing creativity and innovation in media companies look beyond their own disciplinary boundaries to a limited degree. Exceptions exist, but seldom in terms of empirical studies. Storsul and Krumsvik's (2013) endeavor to identify what media innovation is starts off from the business and economics literature, for example by adapting Francis and Bessant's four Ps of innovation (2005) to the field of media. Likewise, Dogruel's (2014) conceptual analysis of the characteristics or attributes of media innovations distinguishes between the research of media innovations as products on the one hand and media innovations as processes on the other. Her attempt to bridge the chasm between the innovation literature and the media economics and management literature shows how the innovation litera- 
ture might beneficially inform studies of media innovations, as well as the limitations of transferring approaches across these disciplinary boundaries, largely due to the specific characteristics of media innovations. Limitations concern for example how "newness" and creativity are key elements of media production, however considering each new film, newspaper, or episode of a TV show as an innovation makes little sense (Dogruel 2014). We should also recall the value of a Systems Model of Creativity and how creativity is in essence a collective endeavor situated between agency and structure. The output of journalism is creative even if, or exactly because, journalists "become inculcated into their profession" and "absorbed into a social organization that has its own culture, its own set of logics and its own traditions and history" (McIntyre 2012: 104). Relatedly, the importance of formats and genres in television production does not invalidate produced content as creative output. Indeed, as McIntyre (McIntyre 2012: 120) argues, agency/structure is not a matter of 'either/or. structures are capable of providing enabling (creative) possibilities. However, even if a new episode of a TV show is an outcome of creative work, a new episode is very rarely an innovation. Instead, innovations in media content need to be assessed as products that diverge from existing formats or genres.

The relatively small number of attempts to study changes in the media industries using notions and perspectives from the innovation literature does not mean that communication and media scholars have ignored media innovation-related topics as research areas. Quite the contrary, changes and developments in the media industry have been thoroughly addressed and discussed. Still, these studies are theoretically framed with an emphasis on concepts and approaches that are quite different from those typically employed in innovation studies in the business literature. Hence, few studies attempt to distinguish between types of media innovations; few studies apply a business model approach to study media innovations (with some exceptions, see, e.g., Günzel and Holm 2013); few studies address the complexity and riskiness of media innovation processes, or the role of different innovation and management capabilities in media innovation processes; and few studies look into the initial creativity-dependent phases of media innovation processes (with some exceptions, see, e. g., Steensen 2009). To some extent, it might be the case that the types of questions and topics addressed in the larger business and economics literature have a limited relevance for investigations of media innovations. For example, scholars who explicitly address and advocate the need for innovation in order to ensure the continued sustainability for the news media and for media companies situate media companies as placed between commerce and commons, emphasizing the need for commons-based principles as fundamental for innovations in the media (see, e.g., Pavlik 2013).

The stark changes in the media scene over the last few years also imply numerous and very broad avenues for research, roughly linked to at least three interdependent trajectories of change: technological development, economic challenges, and changing audience patterns of accessing media content. The changes and innovations in media products, services, processes, and business models over the last twenty years 
are quite remarkable. We have witnessed the incessant growth of the tech quintet Amazon, Google, Microsoft, Apple, and Facebook, whose global dominance has to a large extent changed the game also for incumbents in the media industry. In 2016, Facebook and Google attracted one fifth of global advertising spending (Kollewe 2017), and the dominance of these two players is usually emphasized when attempting to explain the dwindling revenues from advertisements in incumbent media firms, "especially noticeable in the newspaper, magazine, and radio businesses" (Couldry and Turow 2014: 1715). We have moreover witnessed tech companies disrupting the markets of the music and television industries with value propositions aligned with the preferences of digital audiences; and new media streaming services apparently mitigate challenges with piracy and illegal file-sharing, paving the way towards service offerings customers are willing to pay for. Media streaming services represent an interesting case for discussing innovation and creative change thinking at the intersection between a complex value network of stakeholders, and in the following, I will address these types of services with a particular emphasis on music streaming services.

The development and massive adoption of music streaming services over a relatively short time span is worth investigating using notions and perspectives from the innovation literature. I will emphasize three points: First, music streaming services are “offers you can't refuse”. For music listeners, the value propositions these services represent are almost too good to be true. Second, these services represent innovations in value capture mechanisms with audiences paying for access to rather than ownership of music, suggesting that we might also consider whether music streaming as an innovation represents the final triumph over piracy. Third, an ecosystems perspective on innovation allows for an analysis of how music streaming services represent co-creative innovations of technologies and markets.

First, music streaming services tie in well with a customer- and experience-centric approach to innovation and the service-dominant logic of marketing. Spotify, Apple Music, and Deezer are examples of services that start from what customers want (as a first step) towards optimizing business performance (as a whole). The value propositions of these services as providing access to an abundant catalogue of music "anytime and anywhere" reflect the convenience value of these types of services (Oyedele and Simpson 2018). Music streaming services also have added-value characteristics compared to previous formats of owning and accessing music, most notably the efforts made by service providers to distinguish their service offerings in terms of optimizing personalized recommendations. And whereas music streaming services have replaced ownership with access, music listeners retain a sense of ownership, e. g., by sorting and curating their music in local libraries and playlists, which moreover enables different types of listening practices (Hagen 2015; Sinclair and Tinson 2017). With regard to the design and continuous innovation typical of these types of services, it may also be worthwhile to consider some of the key points from Vargo and Lusch's (2004) service-dominant logic. The service-dominant logic is a marketing perspective with 
evident relevance for understanding innovation in goods and services. Companies can only offer value propositions, while actual value is always co-produced by the customer, as perceived and determined by the customer on the basis of value in use. Given that the customer is always a co-producer of service experience and hence service value, what is offered and how that offer is experienced and put to use cannot be separated. Singling out the music streaming experience or the value of such services is as such impossible, as also reflected in the different patterns of realizing the value propositions of these types of services (Hagen 2015; Hagen and Lüders 2017).

Interesting in this context are also the different needs for the streaming service provider to monetize on offerings: Apple does not depend on Apple Music as a revenue machine. Instead, Apple Music is part of the Apple ecosystem, where revenue primarily flows from the sale(s) of iPhones (Apple 2017) and where other services are part of what creates value for customers. In other words, Apple has a significantly larger leeway in terms of generating revenue from specific services compared to single-service providers such as Spotify and Deezer. As Apple thus can be said to build a service-system surrounding and providing added value to the tangible products the company sells, Apple also serves as an example of the change from a goods-dominant to a service-dominant logic, that is, "a reoriented philosophy that is applicable to all marketing offerings, including those that involve tangible output (goods) in the process of service provision" (Vargo and Lusch 2004: 2).

Second, the combined value added with music streaming services compared to previous ownership-based formats of music listening has been perceived as significant enough for music listeners to largely discard purchases of physical and digital formats as well as illegal downloading (Hampton-Sosa 2017; Sinclair and Tinson 2017). After years of losing revenue, 2016 marked a milestone year for the recorded music market industry, with an increase in revenue and with streaming being a driver for growth. Revenues from streaming increased by $60.4 \%$ and the number of paid subscribers to streaming services passed 100 million (International Federation of the Phonographic Industry (IFPI) 2017). Given that some services have a two-tire freemium and premium model, the number of active users is much higher. Spotify reports to have 159 million monthly active users, including 71 million premium subscribers (Spotify Technology 2018). Research relatedly suggests that music streaming services appear to be offerings users are willing to pay for (Kim, Nam, and Ryu 2017). These legal services appear to some extent to be displacing illegal file sharing and downloading, and it may consequently appear legitimate to propose that music streaming represents the victory over piracy. Danaher, Smith, and Telang (Danaher, Smith, and Telang 2017: 71) likewise argue that research provides "strong evidence that rightsholders can reduce piracy and increase legal consumption by offering their content in more convenient channels". Yet, we might question whether streaming represents a triumph over piracy. Spilker (2017: 117) instead claims that streaming services represent the victory of piracy: "Piracy has forced the music industry to accept, reluctantly, business models and services that it from the outset fought fiercely against". That 
is, the massive popularity of illegal file sharing posed such challenges for the music industry that they had no choice but to succumb to a model more in line with what music listeners, once accustomed to having the world of music at their fingertips, would find satisfactory.

Third, it might be useful to examine music streaming services as innovations from a co-creative perspective. An ecosystems perspective on innovation posits that technologies and markets are shaped by co-creation of value: The context of innovations extends to include multiple actors and institutions and their interactions (Akaka, Vargo, and Wieland 2017). Before proceeding, it is worthwhile to revisit how internet-distributed services have changed and perhaps disrupted how the music industry works. The challenges for the incumbents in the music industry concern how companies outside the music industry introduced technologies that fundamentally changed the value propositions, and consequently also the value chain and the revenue mechanisms. This development must be situated historically and with regard to the challenges experienced with illegal sharing of music in the late $1990 \mathrm{~s}$ and early $2000 \mathrm{~s}$. The music industry responded to the upsurge of illegal uploading and downloading of digital music by prosecuting illegal peer-to-peer services and individuals who illegally shared files (Mossoff 2015), and no real efforts were made to develop legal alternatives for purchasing digital music. Legal music services such as Apple's iTunes Music Store and streaming-services such as Spotify required cooperation and deals with record labels in the process of developing and launching their services, but it remains symptomatic that the existing business models in the music industry have been challenged and disrupted by actors from the tech industry. A service-ecosystems approach to music streaming services foregrounds questions concerning ongoing interactions among the multiple actors and institutions (understood as rules, norms, and meanings enabling and constraining human action) and how "technologies and markets are shaped by value co-creation and the ongoing negotiation and recombination of overlapping and intersecting institutions” (Akaka, Vargo, and Wieland 2017: 44).

This account of the emergence of music streaming services has emphasized how tech companies collaborating with the recorded music industry have managed to finally put end-users first with a model with a commercial appeal. However, I introduced this chapter with a call for addressing media innovations also from a critical perspective.

\section{Critical innovation studies}

In the innovation literature "new" means "better", and while exceptions exist, this assumption has remained largely unchallenged. Anderson et al. (2014: 1320) hence pertinently suggest that the existing literature suffers from what they term an "innovation maximization fallacy", which describes "the implicit, untested, and critically 
suspect set of presumptions that has grown out of proinnovation bias' remaining unchallenged. Innovation maximization fallacy is that 'all creativity and innovation is good; and the more the better"'. Even if we were to accept the premise that more innovation and creativity is always good, we may follow up, asking for whom it is good or better? Given the intrinsic link with the dominant belief in continued economic growth, the question answers itself: successful innovation is not necessarily good for everyone. Suchman and Bishop (2000: 331) relatedly argue that innovation "is a politicized construct taken up by specific actors and made to work in particular ways", and commonly innovation is appropriated for change agendas aimed at reproducing existing economic orders. As such, the authors reason, innovation frames conservative projects. Others chime in, pointing to how innovation studies within a managerial framework are limited and uninventive, always privileging those already in powerful positions (Ehn, Nilsson, and Topgaard 2014). Hence, critical approaches and inquiries that address the consequences of innovation and creativity are acknowledged to hold promise to advance the field forward (Anderson, Potočnik, and Zhou 2014).

Such calls for critical innovation studies resonate with several of Feenberg's (1999) key points when he discusses the central place of critical theory for addressing or questioning technology and technological development. Feenberg's approach is explicitly relevant for understanding innovation as a consequence of the central role assigned to technological advancement for understanding innovation processes. Feenberg's critical approach is also implicitly relevant as dominant accounts of technological development and innovation share the same narrative of an inevitable progress. Critical theory is needed in order to unpack how the technical and the social domains are entangled and how technology is value-laden, i.e., technology as a means forms a way of life that includes ends. This stance implies that technology cannot be merely reduced to functions and raw materials, or an essence understood as rational control and efficiency. Rather, Feenberg argues the essence of actual technology as we encounter it in all of its complexity is not simply an orientation toward efficiency. Humans are not governed solely by rationality, which implies that a rational criterion such as technical efficiency does not in itself account for the success of some innovations and the failure of others. Neither are technical principles alone sufficient to determine the design of actual devices. Hence, agreeing with the constructivist approach to technology, Feenberg (1999: 79) argues that "the choice between alternatives depends neither on technical nor economic efficiency, but on the 'fit' between devices and the interests and beliefs of the various social groups that influence the design process". The ultimate path a technology takes is thus determined as much by politics, cultural norms, user agency, and everyday practices as by technical limitations and economic imperatives.

Technological development (or innovation) is therefore not unilinear. Rather, it branches off in many directions and could potentially reach higher levels along several tracks. Once fixed and stabilized, it becomes difficult to see the final stage as other than inevitable. Prior to this stage of closure however, there is often no con- 
sensus on the precise function of new technologies. Rather, technical functions are not pre-given but characterized by a process of interpretative flexibility within which functions are discovered and revised in the course of development and use (see also Uricchio 2008).

Ultimately then, this position has a political significance. Technology, and innovation we may add, is a site of struggle between different interests and stakeholders. To adapt Feenberg's arguments to the objective of this paper, an understanding of innovation as being intrinsically linked to economic growth and human progress comes with a bias towards optimizing business performance. Critical theory affirms human agency in technological development (or innovation processes) and acknowledges that technology (or innovation) is value-laden (and therefore political), yet considers it a central task to discuss alternative means and ends systems.

In closing this chapter, I will return to the case of music streaming services, however now with the objective of discussing these from a critical perspective. It is difficult to assess whether the music streaming model has reached a final closure and hence reached a stage where the way music streaming works is seen as inevitable. It would nevertheless be worth investigating whose interests have come to dominate the current model and with what consequences. I will address two closely connected points. First, I will point to the unresolved challenge of how artists should be paid. Second, I will discuss music streaming services as innovations in the interests of the big players.

Whereas the upsurge of music streaming services is considered within an optimistic framework by the music industry (International Federation of the Phonographic Industry (IFPI) 2017), mainly due to increasing revenues from such services, challenges remain for the music industry stakeholders as well as the music streaming services. Whether the model is economically sustainable for the music streaming providers is also uncertain. Revenues from music streaming services come from the subscription fees of individual users. For two-tire services such as Spotify, some additional revenue comes from advertising, yet premium pays off more than freemium (Sinnreich 2016). The business logic and revenue structure of streaming services depart from previous models based on the purchase of physical albums and music as digital files. Instead of a fixed royalty for albums and songs sold, streaming services calculate payments to labels (and indirectly artists) based on a pro-rata system. This business logic means there is no direct link between the music streamed by individual users and the revenues generated for artists. Instead, artists are paid (indirectly via their labels) a percentage of the streaming service's overall monthly revenue (from subscription fees) as allocated based on their share of the total number of streams (Marshall 2015; Maas $\varnothing$ 2014; Sinnreich 2016). As this revenue model breaks fundamentally with the model of fixed royalty per album (or digital file) sold, it has been difficult to establish a feasible plan for distributing revenues, particularly from labels to artists. It is still unclear how revenues from music streaming services can be distributed in fair and transparent ways in complex value networks encompassing consumers, streaming service provid- 
ers, record labels, composers, and musicians. What is clear is that music streaming services, representing an acclaimed business model innovation, are a site of struggle between different interests, and a struggle where the interests of smaller players in the music industry are not catered very well for. A pertinent question is whether these revenue models are still open for negotiation or whether they have reached a stage of closure.

Strongly related to the first point, it appears that music streaming services are innovations in the interests of the big players; the streaming model basically reproduces the existing economic order of the music industry. As pointed out by both Marshall (2015) and Nordgård (2016), streaming as related to digitization does not seem to fundamentally change industry structures, challenge existing power relations, or support independent and small labels. Quite the contrary, streaming appears to consolidate the long-established power structures and dynamics of the recording industry. According to Marshall, this skew towards major labels is a consequence of the revenue model, which is "beneficial to artists and labels who receive a high number of streams because it means that they receive a high proportion of income regardless of how many paying users actually streamed their music" (Marshall 2015: 185). Relatedly, Marshall argues, this consumption logic benefits artists and labels with extensive back catalogues.

This hunt for large numbers of streams leads to a situation where labels have to optimize the visibility of their catalogues. We may add that streaming users are actively encouraged to explore the vast libraries of music available, for example through editorial playlists and personalized recommendations. Such features clearly add value to these services, but it also raises the question of the constellation of music being promoted. Spotify argues that it is a strength that people use Spotify to discover new music and that users listen to a greater variety of artists, and moreover points to its programmed features (e.g., Discover Weekly and Daily Mix) as "driving this growth in artist diversity" (Erlandsson and Perez 2017: unpaginated). With regard to information providers and search engines, Gillespie (2017: 64) argues that "those interested in having their information selected as relevant will tend to orient themselves toward these algorithmic systems, to make themselves algorithmically recognizable”. Applied to music streaming services, we may hence ask whether this game can be played, and if so, who has the resources to do so.

\section{Conclusion}

In this chapter, I have argued that the business and marketing literature on innovation and creativity might contribute notions and perspectives that help open up new avenues for research on innovation processes and innovations in media industries. Importantly and as a consequence of the dual role of media as commerce and 
commons, media and communication scholars are likely better (but not uniquely) positioned to investigate media innovations than scholars from the business and marketing fields. Rather than disqualifying the latter, this assertion is merely intended to emphasize the importance of considering "value" and "innovation" as concerned with a much broader scope than what is common within a neo-liberalist focus on economic growth, profitability, and business-centric metrics. Hence, when communication scholars cross disciplinary boundaries and consider how theoretical notions and perspectives from the management and marketing literature might function as analytical lenses for addressing media innovations, they must bring with them their critical thinking.

The substantial changes that have characterized the media industries over the last twenty years, particularly with regard to technological development, economic challenges, and changing audience patterns of accessing media content, call for continued scholarly attention. In conclusion, I will highlight three important approaches for studying media innovations. First, a business model approach to the study of media innovations might have much to offer in terms of providing an integrated framework for investigating value propositions, target segments, the structure of value networks required for constructing and delivering a media service, as well as value-capture mechanisms. Second, "the media experience" has possibly never been as fragmented and individualized as in our time, evidently as a consequence of technological development. This calls for a reinvigorated scholarly interest in audience/user studies. These first two approaches are not very prevalent in studies of media innovations. The third approach, however, is firmly rooted in the scholarly legacy of our discipline: When media and communication scholars address technological development and innovation, they do so very often from a critical theory perspective. Questioning innovation is ultimately a core concern for the study of media innovations and also suggests that communication studies has much to offer to the business and marketing literature, particularly given the burgeoning realization that the innovation literature suffers from a pro-innovation bias.

\section{References}

Akaka, Melissa A., Stephen L. Vargo \& Heiko Wieland. 2017. Extending the context of innovation: The co-creation and institutionalization of technology and markets. In Tiziana Russo-Spena, Cristina Mele \& Maaria Nuutinen (eds.), Innovating in Practice: Perspectives and Experiences, 43-57. Cham: Springer International.

Amabile, Teresa M. 1988. A model of creativity and innovations in organizations. Research in Organizational Behavior 10(1). 123-167.

Anderson, Neil, Kristina Potočnik \& Jing Zhou. 2014. Innovation and creativity in organizations. Journal of Management 40(5). 1297-1333.

Apple. 2017. Apple reports fourth quarter results. https://www.apple.com/newsroom/2017/11/ apple-reports-fourth-quarter-results/. 
Burt, Ronald S. 2004. Structural holes and good ideas. American Journal of Sociology 110(2). 349-399.

Christensen, Clayton M. 1997. The innovator's dilemma: When new technologies cause great firms to fail. Boston: Harvard Business School Press.

Christensen, Clayton M., Michael Rayonr \& Rony McDonald. 2015. What is disruptive innovation? Harvard Business Review 93(12). 44-53.

Cohen, Wesley M. \& Daniel A. Levinthal. 1990. Absorptive capacity: A new perspective on learning and innovation. Administrative Science Quarterly 35(1). 128-152.

Couldry, Nick \& Joseph Turow. 2014. Advertising, big data and the clearance of the public realm: Marketers' new approaches to the content subsidy. International Journal of Communication 8, http://ijoc.org/index.php/ijoc/article/download/2166/1161.

Crossan, Mary M. \& Marina Apaydin. 2010. A multi-dimensional framework of organizational innovation: A systematic review of the literature. Journal of Management Studies 47(6). 1154-1191.

Csikszentmihalyi, Mihaly. 2014. Society, culture, and person: A systems view of creativity. In Mihaly Csikszentmihalyi (ed.), The systems model of creativity, 47-61. Dordrecht: Springer Netherlands.

Csikszentmihalyi, Mihaly (ed.). 2014. The systems model of creativity. Dordrecht: Springer Netherlands.

Csikszentmihalyi, Mihaly \& Robert K. Sawyer. 2014. Shifting the focus from individual to organizational creativity. In Mihaly Csikszentmihalyi (ed.), The systems model of creativity, 67-71. Dordrecht: Springer Netherlands.

Danaher, Brett, Michael D. Smith \& Rahul Telang. 2017. Copyright enforcement in the digital age: Empirical evidence and policy implications. Communications of the ACM 60(2). 68-75.

Dewar, Robert D. \& Jane E. Dutton. 1986. The adoption of radical and incremental innovations: An empirical analysis. Management Science 32(11). 1422-1433.

Dogruel, Leyla. 2014. What is so special about media innovations?: A characterization of the field. The Journal of Media Innovations 1(1).

Drucker, Peter F. 1985. Innovation and entrepreneurship: Practice and principles. Oxford: Harper \& Row.

Ehn, Pelle, Elisabet M. Nilsson \& Richard Topgaard (eds.). 2014. Making futures: Marginal notes on innovation, design, and democracy. Cambridge, MA, London: The MIT Press.

Erlandsson, David \& Jomar Perez. 2017. Listening diversity increases nearly 40 percent on spotify. https://insights.spotify.com/br/2017/11/02/listening-diversity-spotify/. (2 November, 2017.)

Ettlie, John E., William P. Bridges \& Robert D. O'Keefe. 1984. Organization strategy and structural differences for radical versus incremental innovation. Management Science 30(6). 682-695.

Fagerberg, Jan. 2006. Innovation: A guide to the literature. In Jan Fagerberg, David C. Mowery \& Richard R. Nelson (eds.), The Oxford handbook of innovation, 1-29. Oxford: Oxford University Press.

Fast Company. 2018. The world's 50 most innovative companies 2018. https://www.fastcompany. com/most-innovative-companies/2018. (20 February, 2019.)

Feenberg, Andrew. 1999. Questioning technology. London: Routledge.

Foss, Nicolai J. \& Tina Saebi. 2017. Fifteen years of research on business model innovation. Journal of Management 43(1). 200-227.

Francis, Dave \& John Bessant. 2005. Targeting innovation and implications for capability development. Technovation 25(3). 171-183.

Garcia, Rosanna \& Roger Calantone. 2002. A critical look at technological innovation typology and innovativeness terminology: A literature review. Journal of Product Innovation Management 19(2). 110-132. 
Gillespie, Tarleton. 2017. Algorithmically recognizable: Santorum's Google problem, and Google's Santorum problem. Information, Communication \& Society 20(1). 63-80.

Green, William \& Robert Cluley. 2014. The field of radical innovation: Making sense of organizational cultures and radical innovation. Industrial Marketing Management 43(8). 1343-1350.

Günzel, Franziska \& Anna B. Holm. 2013. One size does not fit all - understanding the front-end and back-end of business model innovation. International Journal of Innovation Management 17(1). $1-34$.

Hagen, Anja N. 2015. The playlist experience: Personal playlists in music streaming services. Popular Music and Society 38(5). 625-645.

Hagen, Anja N. \& Marika Lüders. 2017. Social streaming?: Navigating music as personal and social. Convergence 23(6). 643-659.

Hampton-Sosa, William. 2017. The impact of creativity and community facilitation on music streaming adoption and digital piracy. Computers in Human Behavior 69. 444-453.

Heidenreich, Sven, Tobias Kraemer \& Matthias Handrich. 2016. Satisfied and unwilling: Exploring cognitive and situational resistance to innovations. Journal of Business Research 69(7). 2440-2447.

Hult, G.Tomas M., Robert F. Hurley \& Gary A. Knight. 2004. Innovativeness: Its antecedents and impact on business performance. Industrial Marketing Management 33(5). 429-438.

Hurley, Robert F. \& G. T. M. Hult. 1998. Innovation, market Orientation, and organizational learning: An integration and empirical examination. Journal of Marketing 62(3). 42-54.

International Federation of the Phonographic Industry (IFPI). 2017. Global music report 2017: Annual state of the industry. London.

Kim, Jiwhan, Changi Nam \& Min H. Ryu. 2017. What do consumers prefer for music streaming services?: A comparative study between Korea and US. Telecommunications Policy 41(4). 263-272.

Kline, Stephen J. \& Nathan Rosenberg. 1986. An overview of innovation. In Ralph Landau \& Nathan Rosenberg (eds.), The positive sum strategy: Harnessing technology for economic growth, 275-304. Washington, DC: National Academies Press.

Kollewe, Julia. 2017. Google and Facebook bring in one-fifth of global ad revenue. https://www. theguardian.com/media/2017/may/02/google-and-facebook-bring-in-one-fifth-of-global-adrevenue. (2 May, 2017.)

Kristensson, Per, Herbjørn Nysveen \& Helge Thorbjørnsen. 2017. Why customers do and do not switch. In Marika Lüders, Tor W. Andreassen, Simon Clatworthy \& Tore Hillestad (eds.), Innovating for trust, 353-371. Cheltenham: Edward Elgar.

Küng, Lucy. 2008. Innovation and creativity in the media industry: What? Where? How. In Cinzia Dal Zotto \& Hans van Kranenburg (eds.), Management and innovation in the media industry, 3-14. Cheltenham: Edward Elgar.

Lüders, Marika, Tor W. Andreassen, Simon Clatworthy \& Tore Hillestad. 2017. Innovating for trust. In Marika Lüders, Tor W. Andreassen, Simon Clatworthy \& Tore Hillestad (eds.), Innovating for trust, 1-14. Cheltenham: Edward Elgar.

Maas $\varnothing$, Arnt. 2014. A better way to cut a cake and eat it too: On revenue share in music streaming the value of platform economics. https://medium.com/@arnte/a-better-way-to-cut-a-cake-andeat-it-too-de0c570b8311.

Marshall, Lee. 2015. 'Let's keep music special. F-Spotify': On-demand streaming and the controversy over artist royalties. Creative Industries Journal 8(2). 177-189.

McDermott, Christopher M. \& Gina C. O'Connor. 2002. Managing radical innovation: An overview of emergent strategy issues. Journal of Product Innovation Management 19(6). 424-438.

McIntyre, Phillip. 2012. Creativity and cultural production: Issues for media practice. Basingstoke: Palgrave Macmillan. 
Mossoff, Adam. 2015. How copyright drives innovation: A case study of scholarly publishing in the digital world. Michigan State Law Review (3). 955-987.

Nordgård, Daniel. 2016. Lessons from the world's most advanced market for music streaming services. In Patrik Wikström \& Robert DeFillippi (eds.), Business innovation and disruption in the music industry, 175-190. Cheltenham: Edward Elgar.

Oyedele, Adesegun \& Penny M. Simpson. 2018. Streaming apps: What consumers value. Journal of Retailing and Consumer Services 41. 296-304.

Pavlik, John V. 2013. Innovation and the future of journalism. Digital Journalism 1(2). 181-193.

Pine, B. J. \& James H. Gilmore. 1999. The experience economy: Work is theatre \& every business a stage. Boston: Harvard Business School Press.

Prahalad, Coimbatore K. \& Venkat Ramaswamy. 2004. Co-creation experiences: The next practice in value creation. Journal of Interactive Marketing 18(3). 5-14.

Saebi, Tina, Herbjørn Nysveen, Mohammad T. Hossain \& Annita Fjuk. 2017. Designing experiencecentric business models: Wwhat do they look like and how do they influence trust? In Marika Lüders, Tor W. Andreassen, Simon Clatworthy \& Tore Hillestad (eds.), Innovating for trust, 115-130. Cheltenham: Edward Elgar.

Sawyer, Robert K. 2012. Explaining creativity: The science of human innovation, 2nd edn. New York: Oxford University Press.

Schumpeter, Joseph A. 2017. Theorie der wirtschaftlichen Entwicklung. Berlin: Duncker \& Humblot.

Sinclair, Gary \& Julie Tinson. 2017. Psychological ownership and music streaming consumption. Journal of Business Research 71.1-9.

Sinnreich, Aram. 2016. Slicing the pie: The search for an equitable recorded music economy. In Patrik Wikström \& Robert Defillippi (eds.), Business innovation and disruption in the music industry, 153-174. Cheltenham: Edward Elgar.

Spilker, Hendrik S. 2017. Digital music distribution: The sociology of online music streams. Florence: Routledge.

Spotify Technology. 2018. Form F-1 registration statement. New York.

Steensen, Steen. 2009. What's stopping them?: Towards a grounded theory of innovation in online journalism. Journalism Studies 10(6). 821-836.

Storsul, Tanja \& Arne H. Krumsvik. 2013. What is media innovation? In Tanja Storsul \& Arne H. Krumsvik (eds.), Media innovations: A multidisciplinary study change, 13-26. Gothenburg: Nordicom.

Suchman, Lucy \& Libby Bishop. 2000. Problematizing 'innovation’ as a critical project. Technology Analysis \& Strategic Management 12(3). 327-333.

Thompson, Victor A. 1965. Bureaucracy and innovation. Administrative Science Quarterly 10(1). 1.

Tidd, Joseph, John R. Bessant \& Keith L. R. Pavitt. 2005. Managing innovation: Integrating technological, market and organizational change, 3rd edn. Chichester: Wiley-Blackwell.

Uricchio, William. 2008. Television's first seventy-five years: The interpretive flexibility of a medium in transition. In Robert P. Kolker (ed.), The Oxford handbook of film and media studies, 286-305. Oxford: Oxford University Press.

Vargo, Stephen L. \& Robert F. Lusch. 2004. Evolving to a new dominant logic for marketing. Journal of Marketing 68(1). 1-17.

Vargo, Stephen L., Paul P. Maglio \& Melissa A. Akaka. 2008. On value and value co-creation: A service systems and service logic perspective. European Management Journal 26(3). 145-152. 